\title{
Las derrotas de la izquierda y el histórico ascenso del bipartidismo en Nuevo León, México
}

\author{
The defeats on the left and the historical rise of bipartisanship in Nuevo León
}

\author{
Laura Medellín Mendoza*
}

\begin{abstract}
Resumen: En este artículo se analizan las condiciones cultura ideológica y reformas electorales anteriores a la alternancia política (1997) como variables explicativas de las sucesivas derrotas de la izquierda partidaria en Nuevo León. Se considera que en un contexto de debilidad organizativa y de la baja penetración ideológica de los partidos de izquierda, las reformas electorales federal (1977) y local (1987), pensadas desde la estrategia para incentivar la pluralidad en el sistema de partidos, tuvieron más bien el efecto de generar la caracterización de un modelo en donde el PRI aunque mantuvo el predominio, se abrió el espacio tendencialmente hacia un bipartidismo con el PAN. La evidencia que encontramos es que los resultados electorales de 1979 hasta 1994 -periodo antes de la alternancia política en el Estado-, propiciaron gradualmente una conformación legislativa de este corte, en donde la izquierda partidaria quedó reducida y marginada como opción electoral.
\end{abstract}

Palabras clave: reformas electorales, partido hegemónico, bipartidismo, Nuevo León

\begin{abstract}
This article analyzes the ideological culture conditions and previous electoral reforms to the political change (1997) as explanatory variables of the successive defeats of the party left in Nuevo León. It is considered that in a context of organizational weakness and low ideological penetration of the leftist parties, federal and local electoral reforms (1977) (1987), designed from strategy to encourage plurality in the party system, were more while the effect of generating the characterization of a model where the PRI maintained although the prevalence, space opened tends toward bipartisanship with the PAN. The evidence we found is that the election results of 1979-1994-a period before the political change in the State-, gradually led to a legislative creation of this court, where the party left was reduced and marginalized as electoral choice.
\end{abstract}

Keywords: electoral reforms, hegemonic party, bipartisanship, Nuevo León.

\footnotetext{
* Centro de Investigaciones de Tecnología Jurídica y Criminológica, Facultad de Derecho y Criminología, Universidad Autónoma de Nuevo León
} 


\section{Introducción}

En el análisis histórico ha sido un lugar común mencionar que Nuevo León es uno de los estados donde ha existido mayor crecimiento económico, gracias a la saga de industrialización que se desarrolló en la entidad desde finales del siglo XIX. La importancia de la ideología empresarial ha sido un factor clave para explicar la estabilidad política y social. Sin embargo, poco se ha estudiado la trayectoria electoral de los partidos políticos que han cuestionado la tesis del liberalismo económico y que ideológicamente están centrados en la pugna capital-trabajo, los llamados partidos de izquierda: Partido Comunista Mexicano [PCM]; Partido Socialista Unido de México [PSUM]; PMS [Partido Mexicano Socialista]; [PRT] Partido Revolucionario de los Trabajadores y por último el PRD [Partido de la Revolución Democrática]. Históricamente esta izquierda partidaria ha tenido una presencia legislativa limitada y casi marginal en el acceso a cargos de elección popular. En Nuevo León, el PRD heredero de esta tradición de izquierda, ha tenido tendencialmente un diputado desde 1991 hasta 2009; en coalición electoral ha tenido tres [2003] y dos diputados [2012]. En el caso de las alcaldías, ha tenido cinco experiencias de gobierno: tres victorias sólo por sus siglas [2003 y 2012] y dos en coalición en el 2006 (Medellín y Murillo, 2014: 207). ¿Cómo explicar esta baja incidencia electoral?

Partiendo del análisis histórico estatal, enfatizamos el funcionamiento del sistema de partido de corte hegemónico en el contexto de las reformas electorales y la variable específica del poder empresarial para aportar elementos de discusión analizando tres bloques de procesos electorales principales 1979, 1985 y 1991 además de sus respectivas elecciones intermedias 1982, 1988 y 1994.

Nuestro punto de partida, son las elecciones locales de 1979 porque justo dos años antes se había producido una reforma electoral en el ámbito nivel federal, que supondría una mayor pluralidad al flexibilizarse los esquemas legales de participación para los partidos políticos. Localmente, sólo el Partido Acción Nacional de ideología conservadora ejercerá una real competencia al PRI. Posteriormente una reforma local en 1987 también tendría efectos de acrecentar el bipartidismo PRI-PAN. Ante este escenario, las diferentes expresiones de lo que se ha considerado como la izquierda partidaria independiente en sus distintas etapas de vida ha permanecido reducida electoralmente tanto por su debilidad organizativa, por falta de penetración ideológica en el electorado y por la presión del gobierno (incentivando la creación de partidos políticos satélite como contrapeso) para mantener su marginación. Sobre esta última variable, en este trabajo mostramos mayor evidencia empírica. Nuestro cierre de estudio termina en 1994, esto es, las últimas elecciones antes de producirse la alternancia del PAN en la gubernatura en 1997(Medellín, 2011) que es de alguna manera la misma visión ideológica liberal con la que había gobernado el PRI, aunque con diferencia de matices en el discurso, mantienen el mismo interés de la estabilidad del orden productivo económico y político. 


\section{Metodología}

El análisis del caso de Nuevo León, se hará partiendo del sistema de partidos local, enfatizando los resultados electorales de los partidos políticos con registro legal de 1979 hasta 1994. En la presentación de los resultados electorales, tenemos los resultados de diputados locales, gobernador y alcaldías.

En el orden metodológico presentamos primeramente los de diputados locales con el fin de analizar por cada año de elección [concurrente y no concurrente], los resultados electorales para cada partido político con registro legal y su respectiva asignación de curules en el congreso local. Se hace la sistemización, en este caso, para proceder al análisis de forma individual en cada proceso electoral, con el fin de hacer en contexto la aparición y/o fusión de nuevos partidos políticos en cada proceso. Se podrá observar cómo la coyuntura de 1988 cambiará el esquema de participación particularmente para los partidos satélite, lo que hará más clara la tendencia bipartidista en el Estado.

En la presentación de los resultados de gobernador y alcaldías, hacemos un concentrado, ya que estas complementan el argumento de la maximización de votos en dos fuerzas políticas principales [PRI-PAN], teniendo como resultadola constante marginación de votos hacia la izquierda partidaria, PCM-PSUM-PMS-PRD y PRT. Para la construcción de cada corte histórico, se analizaron fuentes bibliográficas, así como las cifras presentadas en las memorias electorales del órgano electoral local, a excepción del año de 1979, 1982 y 1985 para elecciones de gobernador, ya que en estos caso se recurrió al Periódico Oficial del Estado de Nuevo León, al carecer el órgano electoral de memorias para esas fechas. ${ }^{1}$

\section{El sistema político nuevoleonés}

El Nuevo León de los años setenta, no parece distanciarse mucho de las anteriores décadas donde el sistema político local, era en escala regional, una reproducción de lo que ocurría a nivel macro: los poderes meta constitucionales del Poder Ejecutivo tenían un amplio margen de maniobra sobre los otros poderes de gobierno: el legislativo y judicial.

El resto de los actores del sistema político, como medios de comunicación, partidos opositores o gremios sindicales, estaban subordinados o ligados de alguna manera por conveniencia a la jerarquía del partido gobernante.

En Nuevo León, existió esa estabilidad política autoritaria, pero teniendo como una variable predominante de contexto a los empresarios que cultivaron el desarrollo y emporio industrial que le dio la típica caracterología de un estado pujante y de crecimiento económico desde fines del siglo XIX (Cerutti, 1989; Cavazos y Ortega, 2011, 178-181; Vizcaya, 2006).

Los empresarios han sido un factor de apoyo al naciente régimen revolucionario;aunque estos se desligaron de su discurso de justicia social y apelaron a la

\footnotetext{
${ }^{1}$ De 1985, sólo existen memorias electorales para diputados locales y alcaldías.
} 
doctrina del liberalismo cuya articulación de intereses fundada en la libre empresa ha sido el factor ideológico más predominante en la entidad (Sánchez, 2007a: 180-181). Como élite ha buscado que las alianzas entre capital y poder no produzcan dividendos negativos para el crecimiento de sus intereses. En este sentido, hay que resaltar el papel protagónico que protagonizaron en los años treinta contra el proyecto estatista en el gobierno de Lázaro Cárdenas (Saragoza, 2008). Como ha sido investigado por Palacios, su visión ideológica, fomentó en los trabajadores el lema del trabajo y el ahorro, que ayudó en muy buena medida:"[...] a mantener en las grandes empresas de su propiedad un estado de disciplina laboral que ha significado la contención casi absoluta de conflictos colectivos de trabajo" (Palacios, 2004:5). No obstante, la intrínseca relación de los empresarios locales con el gobierno, le dio históricamente un impulso relevante a la modernización tecnológica a la ciudad de Monterrey, la capital (Pérez, 2011b:81).

Complementario de esta estabilidad económica, el fuerte control político de los gobernadores era suministrado por un sistema de partido hegemónico y una estructura corporativizada de demandas clientelares.

En la definición clásica de Sartori, en el sistema de partido hegemónico: “[...] no se permite ni una competencia formal, ni de facto por el poder. A otros partidos se les permite existir, pero como de segunda clase [...] no se les permite competir [...] en términos antagónicos o sobre bases iguales. No sólo la alternancia en el poder no ocurre de facto, sino que esta no puede ocurrir puesto que la posibilidad de una alternancia no es ni siquiera considerada" (Sartori, 1976:230).

Emmerich y Canela lo definen como un: "Sistema de partido hegemónico, cuando existen varios partidos legales, pero sólo como satélites del principal; esto implica que los partidos menores no pueden competir de manera efectiva para alcanzar el poder. México, en la época de hegemonía del partido oficial, entre 1929 y 1988, fue un ejemplo clásico" (Emmerich y Canela, 2010: 459).

En el contexto local, el PAN fue el partido de mayor presencia como figura de recia oposición ante el fraude y la simulación en los procesos electorales desde su fundación en el estado en 1939 (Pérez, 2002a). Su militancia autónoma integrada por ciudadanía de clase media y alta, no corporativizada en los gremios sindicales o populares, le reporta un capital político importante, aunque principalmente focalizada en municipios de alto desarrollo económico como San Pedro Garza García y San Nicolás de los Garza. De hecho, en el primero se reconoce la primera victoria del PAN en 1964.En el segundo, en 1973 obtiene la victoria (Mendirichaga, 2005:172, 214, 222).

En el resto del sistema de partidos, podemos encontrar tanto a la expresión de la izquierda partidaria [el principal el Partido Comunista Mexicano en la clandestinidad] y a los partidos satélite en cuya definición tiene que ver con la gran capacidad de cooptación del sistema político.

Los tradicionales partidos satélites que se formaron al amparo del poder fueron el PARM y el PPS. Este último fundado en 1948 fue un partido ligado a su fundador Vicente Lombardo Toledano, líder obrero de la CROM (Rodríguez, 2005: 142). El PPS apoyó reiteradamente a la candidatos del PRI a la presidencia, a excepción de 1988, que se fue con 
la ola cardenista (Avramow, 1988:17). El PARM se constituyó como partido político en 1954, integrado por ex combatientes de la revolución mexicana (Rodríguez, 2004:156). Su papel básicamente fue hacer alianzas con el PRI para votar en la Comisión Federal Electoral contra los partidos de auténtica oposición a cambio de mantener el registro (Avramow, 1988:17).

\section{La presencia de la izquierda en el Estado}

En Nuevo León, según un estudio, existía una de las nutridas células del Partido Comunista en las industrias, donde casi el 50\% de los miembros del partido eran trabajadores industriales en el año de 1938 (Moreno, 2007:225).De acuerdo a una versión de un militante de la izquierda local, el profesor universitario Roberto Benavides González, señala que la presencia del Partido Comunista en Nuevo León, estaba ligada en un principio a la CTM, dado que uno de los fundadores de la CTM en Nuevo León, Tomás Cueva, era al mismo tiempo, militante del Partido Comunista (Benavides, 2013). ${ }^{2}$ Asimismo señala que "había células del Partido Comunista, sobre todo en zonas fabriles. Ellos tenían obviamente células en Fundidora, tenían zonas [de influencia] en ferrocarriles, cuando eran un partido ilegal, semi-clandestino" (Benavides, 2005).

La historia local nos refiere que el conflicto de la huelga de la Vidriera en 1936, se debió en buena medida a la presencia de los rojos en los sindicatos locales y la demanda del sector patronal para que el gobierno se definiera entre "comunismo y anticomunismo" al permitir la presencia de sus afiliados en los sindicatos (Pérez, 1985:166). ${ }^{3}$

Sin embargo, más allá de esa presencia en los sindicatos locales, no existió una fuerte penetración ideológica del comunismo en el resto de la población nuevoleonesa, además de una orientación también marcadamente conservadora en los medios de comunicación (Smith, García y Pérez, 2008: 11-25). La propia orientación cultural de la región por su cercanía fronteriza con Estados Unidos en un contexto de fuerte presencia de la industria [el valor del trabajo y el esfuerzo] y en donde la influencia de la american way of life tiene un peso considerable en la adhesión de las manifestaciones culturales individualistas y de libre mercado, más que en la propensión de los derechos de igualdad. Esto explicaría que el voto contra el PRI, se fuera con el tiempo, no la izquierda más desdibujada en la región, sino al PAN que articulaba estos principios liberales.

De hecho como la señala Segovia en un análisis de la época: "[hay] una carencia de fuerza del PCM en aquella entidad [Nuevo León], donde el electorado de oposición se mantiene homogéneo en su orientación derechista. No debe perderse de vista el anticomunismo militante de los medios de comunicación locales" (Segovia, 1979:403).

\footnotetext{
${ }^{2}$ Existió una relación de alianzas entre ambas entidades, porque en el nacimiento de la CTM, está ligada a los militantes del Partido Comunista, en donde se compartía en este momento [1936] la lucha contra el imperialismo y la defensa del proletariado, como la vanguardia obrera (Pérez, 1985:155-188).

${ }^{3}$ Esta coyuntura se presentó en el gobierno de Lázaro Cárdenas, para una revisión más exhaustiva de la confrontación entre la élite regiomontana y el cardenismo por su orientación de gobierno de tipo socialista, véase a Saragoza (2008:229-259).
} 
En esto coincide otro analista de la época cuando señala que en el estado había una presencia sensible del Partido Comunista Mexicano desde los años treinta y cuarenta, pero que "fueron desalojados sin mucho esfuerzo de sus posiciones sindicales, campesinas, universitarias, etc." (De León, 1990:31). Organizativamente, el Partido Comunista, en los años setenta estaba en proceso de fuertes pugnas internas por su conducción fielmente estalinista (Aguilar, 1983).

\section{El contexto político de la reforma electoral de 1977}

Aunque existió una reforma electoral local en 1976 en la que se cambia de nombre a la antigua Comisión Estatal de Vigilancia Electoral por el nombre de Comisión Estatal Electoral como un organismo de forma permanente, sus efectos son más organizativos, que de un recambio hacia una autonomía política o de efecto en el sistema de partidos. Su composición interna, en términos estratégicos de control político, sigue siendo la figura del Secretario General de Gobierno como presidente del organismo, pero además se incorpora a un representante por cada partido político registrado, además de tres representantes del poder legislativo, un representante por el poder ejecutivo y un secretario nombrado por la misma comisión. ${ }^{4}$

En términos nacionales, la situación de descrédito de la política nacional había llegado a un punto culminante cuando el PAN declinó tener un candidato a la presidencia de la república, cuando ganó una corriente interna que pugnó por no darle legitimidad a un sistema electoral viciado. Por tanto, el candidato del partido oficial, José López Portillo llegó sin competencia a la presidencia de la república en un contexto de altoabstencionismo. El PPS y el PARM, fieles a su condición de partidos satélite decidieron avalar la candidatura priista (Pérez, Puga y Díaz Santana, 2009:43 - 44).

Esta inédita situación política generó en el sexenio de López Portillo un paquete de reformas destinadas a ampliar las garantías de participación, que una vez promulgada como ley, se conoció como LFOPPE (Ley Federal de Organizaciones Políticas y Procesos Electorales) en 1977. Se facilitaron los requisitos para que la izquierda partidaria lograra su registro como partido político nacional reconocido por el órgano electoral.

Se buscó también como un objetivo secundario que con la apertura institucional se pudiera erradicar la participación ilegal, la terrorista y guerrillera agudizada a raíz del conflicto estudiantil de 1968 (Avramow, 1989:21). Esta reforma estableció un sistema electoral para el poder legislativo de carácter mixto [mayoría y representación proporcional] con predominio de la mayoría, (Aziz, 2000:527). Los partidos políticos, por primera vez en la historia moderna eran considerados "entidades de interés público" recibían prerrogativas fiscales y demás estímulos para hacer campaña. Particularmente esta elección fue precedida por una amnistía a los presos políticos (Woldenberg, 2012:31).

\footnotetext{
${ }^{4}$ Un punto importante de la reforma, es que desaparece la figura de las candidaturas independientes, que habían estado vigentes en la legislación desde 1949 (Covarrubias, 1996:180; 205). Con la reforma electoral del año 2014 se vuelven a introducir en la legislación.
} 
Con esta reforma, los partidos políticos que obtuvieron su registro fueron PCM, PDM y el PST (Modonesi, 2003:29; Medina, 2006: 236). Particularmente hay que hacer notar que el Partido Comunista Mexicano es la formación partidista más antigua del país ya que fue fundado en 1919. Pasó gran parte de su inicio, como ya hemos mencionado en la clandestinidad, aunque en el periodo del presidente Lázaro Cárdenas del Río [1934-1940] logra ser un partido tolerado por el régimen de orientación nacionalista. En los regímenes posteriores es un partido de nuevo clandestino, hasta ser plenamente legal con la reforma de 1977 (De León, 1990: 24).En lo que respecta a los antecedentes históricos del Partido Demócrata Mexicano (PDM) es necesario referirse a los de su organización precedente: la Unión Nacional Sinarquista, "no sólo desde el punto de vista ideológico [de derecha] sino también por cuanto al suministro de cuadros y recursos" (Guillén, 2004: 168). El sinarquismo tiene una herencia de las organizaciones católicas activas durante la pugna Estado-iglesia [conocido como el conflicto cristero] de 1929 (Guillén, 2004:168).

El PST de acuerdo a un autor fue [...] la expresión partidista del grupo de líderes y dirigentes estudiantiles que apoyaron la estrategia de apertura política de Echeverría (llamado aperturos) y que vieron premiados sus esfuerzos de oposición colaboracionista" (Medina, 2006:236). Como señalan otros autores, el Partido Socialista de los Trabajadores (PST) no puede considerarse como un partido de oposición independiente porque se registra su alianza con el PRI enelecciones presidenciales (Carr, 1996:308; Modonessi, 2003:30-31). ${ }^{5}$

Las sucesivas reformas electorales después de 1977, transformaron el sistema de partido hegemónico en uno de partido predominante hacia 1988 en el ámbito federal (Emmerich y Canela, 2010: 475). Sin embargo como veremos localmente el escenario por lo menos hasta antes de 1994, también será de partido predominante, pero con una clara tendencia hacia un bipartidismo.

\section{Elección de diputaciones locales: de 1979 a 1994}

Las elecciones de 1979, evidenciaron que la abstención siguió siendo un problema no resuelto. Como señala un autor, la reforma no penetró en las entidades federativas ni resolvió el viejo problema del fraude electoral (Rodríguez y Guillén, 2004: 288). Ahora bien, el escenario de las elecciones de julio de 1979 no era distinto al pasado reciente.

Como puede verse en la siguiente tabla de la elección de diputaciones locales puede notarse que la izquierda partidaria no aparece con participación. Aunque existió disidencia, esta no necesariamente estaba fortalecida para acrecentar su oposición frente al gobierno. Los obreros de la sección 67 del sindicato minero-metalúrgico de la Fundidora de Hierro y Acero de Monterrey habían conformado una línea crítica al pronunciarse por no votar en las elecciones de 1979. Pero la intervención del gobierno contra los trabajadores fue decisiva,

\footnotetext{
${ }^{5}$ Este partido es el antecedente de lo que sería el PFCRN, [Partido del Frente Cardenista de Reconstrucción Nacional] que dirigió Rafael Aguilar Talamantes, figura muy cuestionada entre la clase política y la verdadera izquierda independiente del PRI por sus alianzas oportunistas.
} 
"se echó abajo el acuerdo, se impuso de nuevo un diputado del PRI en la base obrera y se cerró la posibilidad de una línea crítica dentro del sindicato" (Nuncio, 1982:110). La izquierda, pese a las garantías constitucionales recién legisladas no participa ya sea por su debilidad interna y también afectada por la posición dura del gobierno frente al comunismo. Al respecto señala Nuncio: "[existe un] desplazamiento de la oposición de izquierda representada principalmente en las elecciones de 1979 por el PCM [...] La posición de AMD [Alfonso Martínez Domínguez] frente a la reforma política no conoce ambages ni matices. Está contra ella simplemente" (Nuncio, 1982:114-115). El PAN logra con una votación de $23 \%$ tener un diputado de mayoría relativa [en adelante MR] y 2 de representación proporcional [en adelante RP]. El PRI logra 14 diputados, todos de MR en sus distritos. Los partidos satélite, PARM y PPS tienen una votación de 4 y $3 \%$ respectivamente y logran colar 2 y 1 diputados de RP. Hay que hacer notar que el Partido Comunista Mexicano no aparece con participación electoral.

Tabla 1. Comparativo de votaciones por partido político y asignación de diputaciones locales en el Congreso, año 1979

\begin{tabular}{|l|l|l|c|}
\hline & VOTOS TOTALES & PORCENTAJE & $\begin{array}{c}\text { Asignación de diputados en } \\
\text { el congreso local (MR/RP) }\end{array}$ \\
\hline PRI & 367,302 & $70 \%$ & $14 \mathrm{MR} / 0 \mathrm{RP}$ \\
\hline PAN & 46,772 & $23 \%$ & $1 \mathrm{MR} / 2 \mathrm{RP}$ \\
\hline PARM & 17,346 & $4 \%$ & $0 \mathrm{MR} / 2 \mathrm{RP}$ \\
\hline PPS & 13,079 & $3 \%$ & $0 \mathrm{MR} / 1 \mathrm{RP}$ \\
\hline TOTAL & 449,499 & $100 \%$ & 20 \\
& & & \\
\hline
\end{tabular}

Fuente: Elaboración propia con información del Periódico Oficial del Estado de Nuevo León (1979b, 2-14). Nota. Conforme a la legislación vigente de 1976, se tienen 15 distritos de mayoría relativa y 5 de representación proporcional.

Las elecciones intermedias de 1982 son las que suceden a la mitad del gobierno de Alfonso Martínez Domínguez [1979-1985]. En el ámbito federal, estas elecciones son concurrentes con las elecciones presidenciales donde inicia el gobierno del presidente Miguel de la Madrid Hurtado [1982-1988]. Pero en Nuevo León el antecedente de gobierno fue de mano dura, que no permitió la manifestación crítica a su gobierno, limitando su representación política. De lo anterior da cuenta, entre otros autores, Nuncio cuando señala que este gobernador llamado por la opinión pública "Don Alfonso" reprime las movilizaciones sociales, como en el caso de Tierra y Libertad que resolvía con un "despliegue policiaco y militar obviamente innecesarios. Se trataba más que de someter al orden a los protagonistas, de advertir a la población del poder que poseía y de la manera en que podía usarlo" (Nuncio, 1982:109). 
En ese sentido, su gobierno realiza sumariamente en los hechos como una política de Estado, suprimir todo lo que se moviera y oliera a izquierda social y partidaria, negando derechos consagrados en la constitución; a la fuerza "impone la paz laboral exigida por los empresarios" (Nuncio, 1982:114). De nuevo, uno de los actores sociales que participó activamente en la izquierda corrobora las evidencias que se tenía sobre su gobierno, al señalar que la izquierda regiomontana aunque mínimamente posicionada en los sindicatos y en la universidad pública, fue reprimida por el gobernador Alfonso Martínez Domínguez "muy cabronamente" (Benavides, 2013).

No obstante estas condiciones, en 1982 más que en 1979, se pueden apreciar más la participación de los partidos de izquierda que fueron beneficiados con la reforma. Están los partidos satélites como el PPS, el PARM, agregándose en esta coyuntura el PST y el PDM producto de la reforma de 1977, que tienen una votación al parecer inflada por esta política de beneficiarlos y restar espacios de representación, que en el caso de la izquierda sólo está el PSUM. El Partido Socialista Unificado de México (PSUM) viene a ser un partido heredero del Partido Comunista Mexicano, pero también de una fusión de pequeñas organizaciones de izquierda y de intelectuales surgidas al calor de 1968 (Avramow, 1989:23). Como puede verse en la tabla siguiente, en estas elecciones intermedias, el PRI obtuvo el 64\% de la votación $(551,859)$, el PAN $22 \%$ de los votos $(189,967)$. Pero a continuación lo interesante se presenta cuando los partidos satélite que en esta elección: PARM, PDM, PPS y PST representan votaciones muy pocos creíbles. Cada uno respectivamente tuvo cifras del orden de: 23, 614; 22,185, 32,106 y 22,673 de los sufragios. El PARM y el PPS aumentaron su votación con respecto a las elecciones de 1979, el PDM y PST, con votaciones similares a los primeros. Cada uno de ellos logró un diputado de representación proporcional. Al contrario, el PSUM no pasó del 1\% de la votación, apenas 6, 570 de los votos; por tanto no alcanzó representación congresal.

Tabla 2.Comparativo de votaciones por partido político y asignación de diputaciones locales en el Congreso, año 1982

\begin{tabular}{|l|l|l|c|}
\hline & votos TOTALES & PORCENTAJE & $\begin{array}{l}\text { Asignación de diputados en el congreso } \\
\text { local (MR/RP) }\end{array}$ \\
\hline PAN & 189,967 & $22 \%$ & $0 \mathrm{MR} / 3 \mathrm{RP}$ \\
\hline PRI & 551,859 & $64 \%$ & $21 \mathrm{MR} / 0 \mathrm{RP}$ \\
\hline PARM & 23,614 & $3 \%$ & $0 \mathrm{MR} / 1 \mathrm{RP}$ \\
\hline PSUM & 6,570 & $1 \%$ & $0 \mathrm{MR} / 0 \mathrm{RP}$ \\
\hline PDM & 22,185 & $2.5 \%$ & $0 \mathrm{MR} / 1 \mathrm{RP}$ \\
\hline PPS & 22,106 & $2.5 \%$ & $0 \mathrm{MR} / 1 \mathrm{RP}$ \\
\hline PST & 22,673 & $3 \%$ & $0 \mathrm{MR} / 1 \mathrm{RP}$ \\
\hline VOTOS NULOS & 14,232 & $2 \%$ & 28 \\
\hline TOTAL & 863,206 & $100 \%$ & \\
\hline
\end{tabular}

Fuente: Elaboración propia con información del Periódico Oficial del Estado de Nuevo León (1982a: 1-14). Nota: en 1982 se aumentó el total de representantes populares ya que aumentan los distritos electorales de 15 a 21 y de representación proporcional aumentan a 7 (Covarrubias, 1996:376). 
En 1985, se puede observar que el PRI también domina con una amplia mayoría, muy por encima de lo que la oposición pudo o le permitieron hacer.

Como lo hace notar la tabla, el PRI presenta una ventaja del $62 \%$, por encima del PAN que tiene un votación del 24\%. De los partidos satélite, el PST tiene casi un 5\% de la votación y le sigue el PARM con $2.7 \%$. Contarán cada uno con dos diputados. También con votaciones infladas, PPS y PDM contarán cada uno con un diputado.

En lo que respecta a la izquierda dura hay un escenario con actor nuevo: el PRT. El Partido Revolucionario de los Trabajadores (PRT) es un partido que aparece en este elección, de clara orientación trotskista y que obtuvo su registro en 1981 (Emmerich y Canela, 2010:477; Rodríguez, 2005:56-58). En esta etapa, sólo el PSUM y el PRT, serían las dos expresiones políticas que se consideraron como izquierda independiente. Sus divergencias organizativas, más que ideológicas impidieron formar frente común en términos electorales (Rodríguez, 2005:57). Tanto el PRT y PSUM sumaron juntos un poco más del $1 \%$ de la votación. Es evidente su presencia testimonial, pero como dice el militante del PSUM en esta etapa, Roberto Benavides sobre estos votos: "por lo menos sabíamos que estos [votos] eran genuinamente nuestros" (Benavides, 2013).

Tabla 3. Comparativo de votaciones por partido político y asignación de diputaciones locales en el Congreso, año 1985

\begin{tabular}{|l|l|l|c|}
\hline & Votos totales & Porcentaje & $\begin{array}{l}\text { Asignación de diputados en el } \\
\text { congreso local (MR/RP) }\end{array}$ \\
\hline PAN & 168,386 & $24 \%$ & $2 \mathrm{MR} / 2 \mathrm{RP}$ \\
\hline PRI & 440,564 & $62 \%$ & $24 \mathrm{MR} / 0 \mathrm{RP}$ \\
\hline PPS & 19,340 & $2.72 \%$ & $0 \mathrm{MR} / 1 \mathrm{RP}$ \\
\hline PDM & 18,717 & 2.63 & $0 \mathrm{MR} / 1 \mathrm{RP}$ \\
\hline PARM & 19,387 & $2.72 \%$ & $0 \mathrm{MR} / 2 \mathrm{RP}$ \\
\hline PST & 35,111 & $4.94 \%$ & $0 \mathrm{MR} / 2 \mathrm{RP}$ \\
\hline PRT & 5,710 & $.44 \%$ & $0 \mathrm{MR} / 0 \mathrm{RP}$ \\
\hline PSUM & 3,149 & $0.80 \%$ & $0 \mathrm{MR} / 0 \mathrm{RP}$ \\
\hline VOTOS NULOS & $\mathrm{ND}$ & ------ & 34 \\
\hline TOTAL & 710,364 & $100 \%$ & \\
& & & \\
\hline
\end{tabular}

Fuente: Elaboración propia con información de Comisión Estatal Electoral (1988: s/n) y Comisión Estatal Electoral (1994:216).Nota de la fuente: Se cita el documento de Comisión Estatal Electoral de 1988 porque este condensa la información para el año referido. ND: No disponible. En 1985 se aumenta el total de diputados porque aumenta la distritación de 21 a 26. La representación proporcional aumenta a 8 (Covarrubias, 1996:377).

\section{Elecciones de 1988: el efecto de la reforma de 1987}

Estas elecciones coinciden con las presidenciales de 1988 por lo que es importante considerar el contexto del conflicto político que caracterizaron a las elecciones a nivel nacional. Particularmente este año ha sido muy estudiado por las evidencias del fraude 
electoral cometido básicamente en contra del candidato de la izquierda Cuauhtémoc Cárdenas que provocó un cisma en el sistema político.A pesar de la derrota, no pocos analistas, coinciden que las elecciones de 1988 fueron el parteaguas que marca el inicio de la transición político-electoral en México (González, 1989; Woldenberg, 2012:59-64). A nivel nacional, se suma una gran coalición de partidos y organizaciones para formar el Frente Democrático Nacional (FDN), pero a nivel local observamos más que unificación, una fragmentación.

Los satélites PFCRN, PARM, PPS y PDM fueron juntos con el FDN en la elección presidencial junto con el PMS, entre otros partidos y organizaciones (Avramow, 1989: 13$30){ }^{6}$ pero localmente compitieron por separado, logrando cada uno una votación ínfima. Juntos, no sumaron ni el cuatro por ciento de la votación. Los partidos satélite soltados de la mano del PRI, (muy probablemente como castigo por haberse aliado en la nacional con el FDN) tienen un desplome significativo en su votación. Sólo el PRT a pesar de su registro como partido de izquierda dura,no va en la alianza con el FDN y electoralmente tampoco tiene un porcentaje alto en el ámbito local. ${ }^{7}$

Hay que hacer una aclaración respecto a la aparición de nuevas siglas partidistas en esta elección. El Partido Mexicano Socialista (PMS) es un partido que resultó en 1987 de la fusión del PMT y el PSUM y de otras organizaciones de izquierda como la Corriente Socialista y la Unidad de Izquierda Comunista (Emmerich y Canela, 2010: 476-477; Rodríguez, 2005:58). Por su parte, el PFCRN es la continuación del partido satélite Socialista de los Trabajadores (PST), en 1987 cambio a ese nombre para acomodarse a la ola cardenista (Emmerich y Canela, 2010; 477). El único partido de corte localista que aparece en esta elección es el Partido Liberal Republicano (PLR), con poco atractivo electoral, apenas de un $1.07 \%$ en su nivel de votación.

El PRI dominó con 477,066 votos(70\%) y el PAN consiguió 169,820 votos (25\%). Sólo ellos tienen representación en el Congreso del Estado, el PRI con 25 diputados de MR y uno de RP; el PAN tiene uno de MR y 13 de RP. El resto de los partidos, como hemos mencionado, aparecen fragmentados dados sus bajos resultados electorales y no logran ninguna curul en el Congreso, ni siquiera los satélites. ¿Por qué se da este fenómeno?

La explicación hay que buscarla uno año antes. En 1987, se aprobó una reforma electoral que cambia el contexto de representación legislativa. Producto de la crisis de legitimidad electoral de 1985, se aprobaron cambios a la ley electoral para facilitar la pluralidad partidista en el Congreso. Se mantuvo el sistema mixto de mayoría relativa y de representación proporcional, pero se cambia la fórmula electoral para aumentar de 8 a 14 el número de diputados electos conforme al principio de representación proporcional. En aras de este objetivo de lograr la representatividad se disminuye el umbral electoral, es decir,

\footnotetext{
${ }^{6}$ En total se enumeran 4 partidos con registro legal, 7 sin registro legal y 33 organizaciones de la sociedad civil apoyando la candidatura de Cárdenas en 1988 (López, 2007:33-34).

7 Rosario Ibarra de Piedra, la candidata presidencial del PRT, con una tradición de activismo político en su lucha por la desaparición de estudiantes por la guerra sucia, cuando sucede el fraude de 1988 apoya el frente común junto con el candidato del PAN y del FDN para buscar el esclarecimiento del fraude.
} 
"el porcentaje de votos necesarios para participar en la asignación de curules de representación proporcional"; pasa de 2.5 a 1.5\% (Periódico Oficial del Estado, 1987: 38). ${ }^{8}$

Esta importante señalar que aunque esta reforma esclarezca las intenciones de mejorar la pluralidad, el efecto paradójico que sólo el PAN se benefició con la reforma, por ser el partido opositor de mayor tradición en los votos. Las votaciones infladas de la votaciones para los satélites del orden de 20,000 a 30, 000 votos habían desaparecido en la lógica de gobierno estatal. Por su parte, el PMS y el PRT no habían alcanzado el umbral electoral, con sus votos "electoralmente genuinos".

Tabla 4.Comparativo de votaciones por partido político y asignación de diputaciones locales en el Congreso, año 1988

\begin{tabular}{|c|c|c|c|}
\hline $\begin{array}{c}\text { Partido } \\
\text { Político }\end{array}$ & $\begin{array}{c}\text { Votación } \\
\text { total }\end{array}$ & Porcentaje & $\begin{array}{c}\text { Asignación de diputados en el } \\
\text { Congreso local (MR/RP) }\end{array}$ \\
\hline PAN & 169,820 & $25 \%$ & $25 \mathrm{MR} / 1 \mathrm{RP}$ \\
\hline PRI & 477,066 & $70 \%$ & $1 \mathrm{MR} / 13 \mathrm{RP}$ \\
\hline PARM & 3,976 & $0.58 \%$ & $0 \mathrm{MR} / 0 \mathrm{RP}$ \\
\hline PMS & 6,947 & $1.02 \%$ & $0 \mathrm{MR} / 0 \mathrm{RP}$ \\
\hline PFCRN & 8,501 & $1.25 \%$ & $0 \mathrm{MR} / 0 \mathrm{RP}$ \\
\hline PRT & 1,125 & $0.16 \%$ & $0 \mathrm{MR} / 0 \mathrm{RP}$ \\
\hline PLR & 7,302 & $1.07 \%$ & $0 \mathrm{MR} / 0 \mathrm{RP}$ \\
\hline PPS & 4,906 & $0.72 \%$ & $0 \mathrm{MR} / 0 \mathrm{RP}$ \\
\hline PDM & 2,182 & $0.32 \%$ & $0 \mathrm{MR} / 0 \mathrm{RP}$ \\
\hline Votos nulos & $\mathrm{ND}$ & ------- & 40 \\
\hline TOTAL & 681,825 & $100 \%$ & \\
\hline
\end{tabular}

Fuente: Elaboración propia con información de Comisión Estatal Electoral (1988: s/n) y Comisión Estatal Electoral (1994: 216). ND: No disponible

En 1991, en cuanto a los datos para diputados locales, los resultados son semejantes, aunque en este rubro la distancia entre los partidos más votados es menor. El PRI se alzó con 543,548 sufragios lo que representa el 58.80\%, mientras que el PAN concentró el $32.10 \%$. Con estas votaciones el PRI logra 25 diputados de mayoría relativa y uno de representación proporcional, el PAN 1 de mayoría relativa y 12 de representación proporcional.

Por su parte, en estas elecciones en donde ya aparece el PRD. Este partido formalmente se constituye en 1989 integrado por la movilización ciudadana del Frente Democrático Nacional (FDN) que se constituyó a partir de las elecciones presidenciales de

\footnotetext{
${ }^{8}$ El contexto de esta reforma de ley, es el conflicto postelectoral de 1985. Fue denunciada por el PAN ante la Comisión Interamericana de los Derechos Humanos (CIDH) por el hecho de seguir generando una violación a los derechos humanos en materia política. Se criticó principalmente la organización de los comicios seguía en manos del gobierno, ya que no se había hecho ningún cambio para lograr la autonomía del órgano electoral. La CIDH determinó en su fallo definitivo que la ley electoral de 1987: “[...] no cumple a cabalidad con la protección efectiva del ejercicio de los derechos políticos ni brinda un recurso sencillo, rápido y efectivo ante tribunales independientes e imparciales [...]" (Informe núm.8/91 caso 10.1810, CIDH, citado en Santos de la Garza, 2003:213).
} 
1988. Además se integra con la corriente democrática escindida del PRI y la herencia comunista representada por el PMS (Reveles, 2004:13). ${ }^{9}$ Obtiene el 2.5\% de la votación.

Mientras que la sumatoria del resto de los partidos incluyendo al PRD, PPS, PFCRN, PARM, el PDM y el PLR dieron un total de 33,964 votoses decir, 3.70\%. Esta fue una cifra inferior a los 50,541 que representan el $5.50 \%$ de los sufragios nulos. Cabe destacar que el PRD, logra su primer diputado de representación proporcional.

Tabla 5. Comparativo de votaciones por partido político y asignación de diputaciones locales en el Congreso, año 1991

\begin{tabular}{|l|l|l|c|}
\hline Partido Político & Votación total & Porcentaje & $\begin{array}{l}\text { Asignación de diputados en el Congreso } \\
\text { local (MR/RP) }\end{array}$ \\
\hline PRI & 543,548 & $58.80 \%$ & $25 \mathrm{MR} / 1 \mathrm{RP}$ \\
\hline PAN & 297,076 & $32.10 \%$ & $1 \mathrm{MR} / 12 \mathrm{RP}$ \\
\hline PPS & 2,963 & $0.20 \%$ & $0 \mathrm{MR} / 0 \mathrm{RP}$ \\
\hline PRD & 21,941 & $2.70 \%$ & $0 \mathrm{MR} / 1 \mathrm{RP}$ \\
\hline PFCRN & 2,724 & $0.20 \%$ & $0 \mathrm{MR} / 0$ RP \\
\hline PARM & 2,115 & $0.10 \%$ & $0 \mathrm{MR} / 0 \mathrm{RP}$ \\
\hline PDM & 2,249 & $0.20 \%$ & $0 \mathrm{MR} / 0 \mathrm{RP}$ \\
\hline PLR & 1,972 & $0.20 \%$ & $0 \mathrm{MR} / 0 \mathrm{RP}$ \\
\hline VOTOS NULOS & 50,541 & $4.90 \%$ & 40 \\
\hline Total & 925,129 & $100 \%$ & \\
\hline
\end{tabular}

Fuente: Elaboración propia con información de Comisión Estatal Electoral (1991: s/n). Nota: El (PLR) Partido Liberal Revolucionario perdió su registro. Se mantiene vigente la distritación de 26 de mayoría relativa y la representación proporcional es de 14.

\section{La elecciones de 1994 y la aparición del PT}

Por último, las elecciones de diputados 1994, son concurrentes con las presidenciales, marcadas ya en la historia por la aparición del zapatismo y el asesinato del candidato priista Luis Donaldo Colosio. En esta coyuntura política es importante tratar aparte la aparición del PT (Partido del Trabajo) y del PVEM (Partido Verde Ecologista Mexicano) dentro del sistema de partidos local. El PVEM, más adelante se perfilará hacia un partido colaboracionista con el priismo, aunque en esta etapa todavía no destaca como tal. Nos concentraremos en la aparición del PT sobre todo por la controversia de registrarlo como partido político de izquierda.

El PT participó por primera vez en las elecciones de Nuevo León con un vigor electoral que le permitió sobrepasar en votación a todos los demás partidos pequeños que

\footnotetext{
${ }^{9}$ Sin embargo, el mismo Reveles hace una crítica de considerar al PRD como heredero de la tradición socialista de sus antecesores. Señala que: “[...] su nacimiento se ubica más en la fractura autoritarismodemocracia y mucho menos en la de capital-trabajo" (Reveles, 2004:21). No obstante, los cuadros principales del partido provenían de los restos del PSUM o del PMS, que de alguna manera identificó una crítica al dominio neoliberal que tendrían el PRI o el PAN en sus programas de gobierno. Otro autor señala que los llamados partidos de izquierda, se han alejado del socialismo en sus distintas vertientes y más aún del marxismo (Rodríguez, 2002:25).
} 
también compitieron. El PT obtuvo por si sólo 77,031 sufragios es decir el 5.34\% diferenciándose de los 51,828 votos que reunieron juntos, el resto de los partidos minoritarios PPS, PRD, PFCRN, PARM, PDM y el PVEM (3.60\%). ¿Cómo interpretar que un partido, sin experiencia electoral previa, súbitamente lograra tener por lo menos una mayor incidencia electoral que otros partidos de oposición?

Ante ello, es pertinente recordar la historia del PT el cual tiene sus antecedentes en el movimiento urbano popular que se desarrolló en México desde los años sesentas del siglo pasado, con una serie de luchas reivindicatorias de los trabajadores de la ciudad y del campo.Como lo señala Bolívar, el PT nace a partir de la integración de diversas organizaciones sociales como los Comités de Defensa Popular de Chihuahua y Durango, el Frente Popular de Lucha de Zacatecas, la Coordinadora Nacional Plan de Ayala, además del Frente Popular de Tierra y Libertad entre otros (Bolívar, 2011:175).

En Nuevo León, el movimiento urbano-popular se hizo visible al fundarse en marzo de 1973 la colonia Tierra y Libertad en Monterrey. Esto se hizo con el apoyo de estudiantes de la Universidad Autónoma de Nuevo León y siguiendo el modelo de lucha popular línea de masas entre 1973 y 1980. Éste se consolidó y expandió a 40 colonias con un esquema de trabajo cimentado en la gestión social de los propios colonos. Producto de estas primeras experiencias de lucha urbana se constituye el Frente Popular Tierra y Libertad de Monterrey entre agosto y septiembre de 1976 bajo el liderazgo de Alberto Anaya Gutiérrez, que aglutinó a 24 organizaciones de diversa índole: posesionarios, colonos, inquilinos, choferes, pequeños comerciantes, mercados sobre ruedas y ejidatarios, llegando a un total de 100 mil personas (Sánchez, 2007b: 107).

Esta experiencia de organización territorial preparó el surgimiento de su brazo electoral, el Partido del Trabajo que favoreció su vertebración como partido político de alcance nacional. Sin embargo, en otra formulación de hipótesis sobre el despliegue electoral es que aprovechando su estructura corporativa, desde el salinismo se buscó apoyar con mayores recursos al PT con el objetivo de hacer un contrapeso político al PRD, el cual se había convertido desde 1988 en la verdadera oposición al gobierno del presidente Carlos Salinas de Gortari [1988-1994] (Jáquez, 1994:7; Rodríguez, 2005:67).

Así las cosas, localmente, los resultados electorales de 1994 resultaron muy distintos a los de 1991: el margen de maniobra legislativa del PRI se estrechó a pesar del incremento de diputaciones contemplado en la nueva ley electoral. Por primera vez, esta reducción en la distancia normalmente mayor entre el PRI y el PAN fue una seria advertencia de lo que vendría posteriormente en las elecciones de 1997.

La votación se cerró principalmente entre estos dos partidos como se observa en la siguiente tabla. La diferencia fue de 55,377 sufragios a favor del PRI, en términos relativos la distancia significó un $3.83 \%$. Tres años antes la diferencia entre ambos partidos había sido del $26.70 \%$. Es decir, el PAN recortó la distancia en $22.87 \%$.

La otra revelación a destacar es que el PT que se convirtió desde entonces en la tercera fuerza política-electoral en Nuevo León con dos diputados, desplazando al PRD en el cuarto lugar al que históricamente aparecerá en las siguientes elecciones. Si de acuerdo a la hipótesis de que el PT fue impulsado por el salinismo para desplazar a la izquierda dura 
representada entonces por el PRD, particularmente en Nuevo León podemos afirmar que este podría considerarse como el nuevo partido satélite de los años noventa, ya que se caracterizaría en votar legislativamente con la fracción parlamentaria del PRI en el Congreso del Estado. ${ }^{10}$

Tabla 6. Comparativo de votos y porcentaje por partido político en la elección de diputados locales en 1994.

\begin{tabular}{|l|l|l|c|}
\hline Partido político & Votación total & Porcentaje & $\begin{array}{c}\text { Asignación de diputados en el } \\
\text { Congreso local (MR/RP) }\end{array}$ \\
\hline PRI & 664,358 & $46.03 \%$ & $15 \mathrm{MR} / 7 \mathrm{RP}$ \\
\hline PAN & 608,981 & $42.20 \%$ & $11 \mathrm{MR} / 6 \mathrm{RP}$ \\
\hline PPS & 3,228 & $0.22 \%$ & $0 \mathrm{MR} / 0 \mathrm{RP}$ \\
\hline PRD & 30,968 & $2.15 \%$ & $0 \mathrm{MR} / 1 \mathrm{RP}$ \\
\hline PFCRN & 3,828 & $0.27 \%$ & $0 \mathrm{MR} / 0 \mathrm{RP}$ \\
\hline PARM & 3,938 & $0.27 \%$ & $0 \mathrm{MR} / 0 \mathrm{RP}$ \\
\hline PDM & 2,552 & $0.18 \%$ & $0 \mathrm{MR} / 0 \mathrm{RP}$ \\
\hline PT & 77,031 & $5.34 \%$ & $0 \mathrm{MR} / 2 \mathrm{RP}$ \\
\hline PVEM & 7,314 & $0.51 \%$ & $0 \mathrm{MR} / 0 \mathrm{RP}$ \\
\hline votos nulos & 41,049 & $2.84 \%$ & \\
\hline total & $1,443,247$ & $100 \%$ & 42 \\
\hline
\end{tabular}

Fuente: Elaboración propia con información de Comisión Estatal Electoral (1994: 209). Nota: Se mantienen vigentes los 26 distritos de mayoría relativa (MR) y se aumenta de 14 a 16 la representación proporcional (RP) con la reforma de 1993 (Flores, Pansza y Araiza, 1999:121).

\section{Elecciones de gobernador en 1979, 1985 y 1991}

La votación que consta en actas del Periódico Oficial del Estado de Nuevo León emitidas por el Congreso del Estado que en ese entonces se erigía en Colegio Electoral para validar las elecciones de 1979, indica que la alianza PRI-PARM tuvo un total de 423,123 votos frente al segundo competidor Acción Nacional con una votación de 122,789. El PPS llegó a tener tan sólo 2,793 votos. El Partido Comunista Mexicano no participó con candidato a gobernador. En 1985, el PRI obtuvo 508,912 votos frente al PAN con 183,374 votos. Tendrían una exigua participación: PRT 6,641 votos y PSUM 3,447votos que no son comparables frente a los resultados de los partidos satélite: PPS 26,211 votos PST 39,088 y PDM 20,108 votos. Esto es, sus cifras electorales van del orden de 20 mil a más de 30, 000

${ }^{10}$ Esta denominación que hago puede ser motivo de amplia refutación. El PT ha hecho alianzas con la izquierda, específicamente con el PRD y Convergencia a nivel nacional y a nivel local, pero también con el PAN. En todo caso, se podrá también decir que lo que ha caracterizado al PT es su pragmatismo. Para una revisión de su postura aliancista véase a Bolívar (2011:187). En el reciente proceso electoral del 2015, el PT perdió su registro como partido político nacional al no alcanzar el 3\% de los votos emitidos (La Jornada, 2015). En Nuevo León, el partido conservó su registro local al igual que en otros estados de la república. 
votos. Por último, en las elecciones de 1991, las votaciones entre los dos principales fueron los siguientes: para el PRI 560,140 votos contra 293,854 para Acción Nacional. El PRD, heredero de la tradición de la izquierda, logró la votación más alta que no habían logrado sus antecesores 25,504 votos. Los partidos satélites como se verá tienen un drástico impacto negativo: PPS, PDM, PARM y PFCRN, su fluctuación está en el orden de entre 1,000 a poco más de 2,000 votos que no se comparan por supuesto con las cifras infladas de la anterior votación.

Tabla 7. Comparativo de votaciones totales en tres elecciones de gobernador

\begin{tabular}{|c|c|c|c|c|c|c|c|c|c|c|c|c|c|c|}
\hline $\begin{array}{l}\text { Año } \\
\text { Elección }\end{array}$ & PAN & PRI & PSUM & PRD & PPS & PDM & PARM & PLR & PFCRN & PST & PRT & $\begin{array}{l}\text { VOTOS } \\
\text { NULOS }\end{array}$ & $\begin{array}{l}\mathrm{NO} \\
\text { Reg }\end{array}$ & TOTAL \\
\hline 1979 & 122,789 & $423,123(1)$ & - & - & 2,793 & - & - & - & - & - & - & - & 850 & 549,555 \\
\hline 1985 & 183,374 & 508,912 & 3,447 & - & 26,211 & 20,108 & - & - & - & 39,088 & 6,641 & ND & - & 787,781 \\
\hline 1991 & 293,854 & 560,140 & - & $25,504-$ & 2,149 & 1,601 & 1,126 & 1,533 & 1,978 & - & - & 46,233 & - & 934,118 \\
\hline
\end{tabular}

Fuente: Periódico Oficial del Estado de Nuevo León (1979a, 1-2); Periódico Oficial del Estado de Nuevo León (1985:1) y Covarrubias (1996:208); Comisión Estatal Electoral (1991: s/n).

1. La razón por la que determinadas casillas tienen un guión en lugar del número de votos obedece a diversos motivos entre los que destacan el hecho de que algunos partidos no habían surgido y por ende no participaron en los comicios, otros perdieron el registro como partido político, otros se coaligaron dando origen a una opción política diferente y por ello no se les adjudicaron votos en lo individual y otros no presentaron candidato a gobernador.

En lo que respecta a las votaciones para las alcaldías, hay que señalar es que sólo hasta el año de 1988, es el PAN quien tiene la posibilidad de ganar de forma sostenida [aunque no hay que olvidar sus primeras victorias en los años setenta]. Par la izquierda partidaria que hemos analizado aquí no hay registrada ninguna victoria. Respecto a las divergencias sobre el origen del PT [su origen popular $v s$ apoyo del gobierno], aunque tiene su primera alcaldía en 1994, en este estudio, no lo contamos como victoria de la izquierda partidaria.

Tabla 8. Número de municipios alcanzados por partido político en las elecciones de Nuevo León 1979 - 1994

\begin{tabular}{|c|c|c|c|c|c|c|c|c|c|c|c|}
\hline $\begin{array}{c}\text { AÑO } \\
\text { ELECTORAL }\end{array}$ & PAN & PRI & PRD & PT & PSUM & PPS & PDM & PST & PARM & PCM & TOTAL \\
\hline 1979 & - & 51 & - & - & - & - & - & - & - & - & 51 \\
\hline 1982 & - & 51 & - & - & - & - & - & - & - & - & 51 \\
\hline 1985 & - & 51 & - & - & - & - & - & - & - & - & 51 \\
\hline 1988 & 2 & 49 & - & - & - & - & - & - & - & - & 51 \\
\hline 1991 & 5 & 46 & - & - & - & - & - & - & - & - & 51 \\
\hline 1994 & 6 & 44 & - & 1 & - & - & - & - & - & - & 51 \\
\hline
\end{tabular}

Fuente: Periódico Oficial del Estado de Nuevo León, (1979c: 1-62) (1982b: 1-64); Comisión Estatal Electoral, (1985:67-79) (1988:5671), (1991) (1994:351) 


\section{Conclusiones}

La izquierda partidaria en Nuevo León ha tenido una capacidad reducida para incidir electoralmente. Históricamente aunque ha tenido presencia en los gremios sindicales con la existencia del Partido Comunista, no tuvo una mayor penetración ideológica en el resto del electorado. Las condiciones culturales que propiciaron una vertiente pro empresarial y en donde el perfil del nuevoleonés está mayormente en una escala de valores también conservador han hecho difícil en esta etapa y las siguientes la emergencia dela izquierda con un atractivo mercado electoral. Es por eso que las promesas de pluralidad de reforma electoral de 1977, cae en un terreno poco fértil, ya que no contaba con partidos de izquierda activos. Son los partidos satélites en cada etapa, los que ayudan al régimen a consolidar la imagen de una pluralidad política, en donde la izquierda partidaria asfixiada por su debilidad y también por la experiencia de la represión, sobre todo en la etapa de gobierno de Alfonso Martínez Domínguez queda prácticamente sin alcance de representación proporcional en 1982 y 1985.

La otra reforma importante de 1987, donde se aumenta la representación proporcional y se baja el umbral electoral, no beneficia a nadie de la oposición más que al PAN en la integración de la legislatura de 1988, ni siquiera a la satélite ahora fuera del radar gubernamental. Ahí puede marcarse el inicio del bipartidismo PRI-PAN en el Estado, tendencia que se mantiene en la actualidad. Es importante considerar que si la alianza a nivel federal que tuvieron los partidos satélite y la izquierda con el FDN en 1988, se hubiera replicado en el ámbito local, es decir forzar sólidamente una frente común ideológico para configurarse como una fuerza electoral, tal vez el escenario bipartidista PRI-PAN no se hubiera instalado con tanto facilidad. Sin embargo, la dispersión de los esfuerzos hicieron posible su fragmentación que permanecen hasta ahora.

Sólo hasta 1991 con la aparición del PRD, se logra tener tendencialmente la presencia legislativa aunque mínima de un diputado, al igual que en 1994. Esa será la tendencia en las elecciones posteriores. Los datos complementarios de elecciones de gobernador y alcaldías confirman la concentración de votos en dos partidos, que comparten en buena medida una misma vocación ideológica liberal en la praxis de gobierno. Las referencias históricas que hemos argumentado para explicar el difícil posicionamiento de la izquierda partidaria en la etapa que hemos analizado parece ser un argumento válido para explicar su debilidad hasta el día de hoy. Más aún, el bipartidismo tan marcado en el Estado con la reforma electoral de 2014 se consolidó con el aumento del umbral del 3\% [antes de $1.5 \%$ ] en la votación para conservar el registro partidista. Por lo menos, los resultados del último proceso electoral del 2015 así lo demuestran. Particularmente el PRD pierde su registro como partido local al no alcanzar el 3\% de la votación al igual que otros partidos minoritarios (Comisión Estatal Electoral, 2015). Aunque esta elección otorgó por primera vez la victoria a un candidato independiente en la gubernatura, en la esfera legislativa es la dupla PRI-PAN quien tiene el control político. 
Laura Medellín M., Las derrotas de la izquierda y el histórico ascenso del bipartidismo en Nuevo León, México - The defeats on the left and the historical rise of bipartisanship in Nuevo León, Revista Izquierdas $\mathrm{N}^{\circ} 25$, Octubre 2015, IDEA-USACH, ISSN 0718-5049, pp. 276-295

Los partidos más débiles tienden gradualmente a desaparecer y los que quedan tienen que negociar políticamente por su sobrevivencia como el referido caso del PT. La posibilidad de lograr una pluralidad en el escenario partidista se vuelve todavía más lejana.

Recibido: 14 mayo $2015 \quad$ Aceptado: 12 agosto 2015

\section{Referencias}

Aguilar, M. (1983) La crisis de la izquierda en México. Orígenes y desarrollo. México: Juan Pablos Editor.

Avramow, J. (1989). Los partidos contendientes en 1988. En J. González Graf (comp.), Las elecciones de 1988 y la crisis del sistema político (pp. 13-30).México: IMEP-Diana.

Aziz, A. (2000), Partidos y elecciones. En L. Baca et.al. (coords.)Léxico de la política. México: Flacso, Conacyt, FCE, Heinrich BöllStiftung.

Benavides, R. (2013).Entrevista a ex militante del PSUM en Nuevo León, 27 de junio, Monterrey.

Bolívar, R. (2011). El Partido del Trabajo: su política de alianzas a partir de 2006, Estudios Políticos (22), pp. 173-208.

Carr, B. (2000).La izquierda mexicana a través del siglo XX. México: ERA.

Cavazos I. y Ortega I. (2011), Historia breve Nuevo León. México: FCE, Colegio de México y Fideicomiso Fondo de la Américas.

Cerutti, M. (1989).Burguesía y capitalismo en Monterrey 1850-1910. México: UANL-Claves Latinoamericanas.

Comisión Estatal Electoral (1985). Elecciones Municipales de Nuevo León 1985, Monterrey: Comisión Estatal Electoral.

Comisión Estatal Electoral (1988).Las Elecciones en Nuevo León 1988. Memoria de Actividades y Reflexiones sobre el Proceso Electoral. Monterrey: Comisión Estatal Electoral.

Comisión Estatal Electoral (1991).Elecciones Municipales en Nuevo León 1991.Memorias y Reflexiones del Proceso Electoral. Monterrey: Comisión Estatal Electoral.

Comisión Estatal Electoral (1994).Elecciones de Ayuntamientos y Diputados Locales en Nuevo León 1994. Memorias y Reflexiones del Proceso Electoral. Monterrey: Comisión Estatal Electoral.

Comisión Estatal Electoral (2015). Resultados de las elecciones de diputados locales. Recuperado en http://ceeresultadosweb.azurewebsites.net/eleccionc 2 D.html [Fecha de consulta, 18 de septiembre de 2015].

Covarrubias, J. (1996).Desarrollo político y transición democrática. Nuevo León 1985-1995. Monterrey: Castillo.

De León, M. (1990).Los retos inmediatos de la modernización política de Nuevo León. Monterrey: Asociación Política Antonio I. Villarreal.

Emmerich, G. y Canela, J. (2010). Los sistemas de partidos políticos en la historia de México. En A. Gimate-Welsh y P. Castro (coords.), Sistema político mexicano. Ayer y hoy. Continuidades y rupturas. (pp. 457-489) México: Miguel Ángel Porrúa-Senado de la República LXI Legislatura. 
Laura Medellín M., Las derrotas de la izquierda y el histórico ascenso del bipartidismo en Nuevo León, México - The defeats on the left and the historical rise of bipartisanship in Nuevo León, Revista Izquierdas $\mathrm{N}^{\circ} 25$, Octubre 2015, IDEA-USACH, ISSN 0718-5049, pp. 276-295

Flores, J. Pansza, S. y Araiza, E. (1999), Las leyes electorales de Nuevo León 1825-1997. Semblanza histórico-político-legislativa. Monterrey: Facultad de Derecho y Ciencias Sociales, UANL.

González, J. (1989). La crisis del sistema. En J. González Graf (comp.) Las elecciones de 1988 y la crisis del sistema político (pp. 137-157), México: IMEP-Diana.

Guillén, A. (2004). Partido Demócrata Mexicano. En O. Rodríguez Araujo. La reforma política y los partidos en México (pp.168-178), México: Siglo XXI Editores.

Jáquez, A. (1994).El rastro que deja el hermano mayor del presidente. Las acusaciones contra Raúl Salinas: tráfico de influencias, negocios ilícitos, complicidades, beneficiario de la privatización bancaria, Proceso (942), pp. 6 -14.

López, M. (2007), La encrucijada. Entre la protesta social y la participación electoral (1988), México: Flacso, Plaza y Valdés, Universidad Autónoma del Estado de Hidalgo.

Medellín, L. (2011).Liberalización y gobernabilidad en Nuevo León. Monterrey: UANL.

Medellín, L. y Murillo J. (2014).El sistema político-electoral en Nuevo León. Elecciones y efectos en el sistema de partidos políticos(1979-2012). Monterrey, mimeo en prensa.

Medina, L. (2006).Hacia el nuevo Estado. México 1920-1994. México: FCE.

Moreno, M.G. (2007). El Partido Comunista Mexicano (PCM) y las luchas anticomunistas en México.

En J. Tamayo (coord.), Movimientos sociales, Estado y sistema político en México (pp. 215-239) Guadalajara: Universidad de Guadalajara.

Modonesi, M. (2003).La crisis histórica de la izquierda socialista mexicana. México: Casa Juan Pablos, Universidad de la Ciudad de México.

Nuncio, A. (1982). El Grupo Monterrey. México: Nuevo Imagen.

Mendirichaga, R. (2005). Acción Nacional. Oposición y gobierno en Nuevo León. México: s/e.

Periódico La Jornada (2015). El PT pierde el registro; INE confirma que obtuvo 2.99 de votos. Recuperado en http://www.jornada.unam.mx/ultimas/2015/08/22/el-pt-pierde-el-registro-se-confirmaque-obtuvo-2-99-de-votos-6662.html [Fecha de consulta 17 de septiembre de 2015].

Periódico Oficial del Estado de Nuevo León (1979a).Decreto porque el que se declaran válidas las elecciones de 1 de julio, núm. 234 del 5 de julio, Decreto 84, pp.1-2.

Periódico Oficial del Estado de Nuevo León (1979b).Acta núm. 331 - LXI -79, núm. 81, 6 de julio de 1979, pp. 2-14.

Periódico Oficial del Estado de Nuevo León (1979c).Actas electorales de elecciones municipales del 2 de diciembre de 1979, núm. 150, 12 de diciembre, pp. 1-62.

Periódico Oficial del Estado de Nuevo León (1982a).Acta núm. 325-LXII-82, núm. 82, 9 de julio de 1982, pp.1-14.

Periódico Oficial del Estado de Nuevo León (1982b).Actas electorales de elecciones municipales del 14 de Noviembre de 1982, núm. 141, 19 de noviembre pp. 1-64.

Periódico Oficial del Estado de Nuevo León (1985). Se declaran válidas las elecciones verificadas el día 7 de julio, núm. 84, 12 de julio, decreto núm. 288, p.1.

Periódico Oficial del Estado (1987). Exposición de motivos de la Ley Electoral del Estado de Nuevo León, núm. 64, 27 de mayo, decreto núm. 94, pp.1-10.

López, M. A. (2007).La encrucijada. Entre la protesta social y la participación electoral (1988). México: Flacso, Plaza y Valdés, Universidad Autónoma del Estado de Hidalgo.

Palacios, L. (2004).Respuestas regionales a la globalización: capitalismo familiar y cambios en las relaciones laborales en Monterrey. Tesis doctoral, Universidad de Utrecht, Holanda.

Pérez, E. (1985). En el sexenio de Lázaro Cárdenas. En A. Martínez Verdugo (ed.),Historia del comunismo en México(pp. 151-188). México: Grijalbo. 
Laura Medellín M., Las derrotas de la izquierda y el histórico ascenso del bipartidismo en Nuevo León, México - The defeats on the left and the historical rise of bipartisanship in Nuevo León, Revista Izquierdas $\mathrm{N}^{\circ} 25$, Octubre 2015, IDEA-USACH, ISSN 0718-5049, pp. 276-295

Pérez, G. (2002a). Los primeros años del PAN en Nuevo León. 1939-1946.Monterrey: Facultad de Filosofía y Letras, UANL.

-------- (2011b). La ciudad de Monterrey y los discursos locales de modernización: reconstruyendo la esfera pública en 1933. Estudios de Historia Moderna y Contemporánea de México (42), pp. 75-108.

Pérez, G. Puga, A. y Díaz-Santana, H. (2009). Memoria histórica de la transición democrática en México, 1977-2007: Documentos básicos para entender el cambio político. México: Cámara de Diputados, LX Legislatura, Miguel Ángel Porrúa, UNAM.

Reveles, F. (2004).Partido de la Revolución Democrática. Los problemasde la institucionalización. México: UNAM, Gernika.

Rodríguez, O. (2002). Izquierdas e izquierdismo. De la Primera Internacional a Porto Alegre. México: Siglo XXI Editores

Rodríguez, O. (2005).Los partidos políticos en México. Origen y desarrollo. En O. Rodríguez y C. Sirvent, Instituciones electorales y partidos políticos en México (pp. 13-82). México: Jorale Editores.

Rodríguez, O. y Guillén A. Las elecciones después de la reforma política. En O. Rodríguez Araujo, La reforma política y los partidos en México (pp. 278-291). México: Siglo XXI Editores.

Sánchez, V. (2007a) Los empresarios en Monterrey en la transición mexicana a la democracia. En I. Ortega, Nuevo León en el Siglo XX. La industrialización. Del segundo auge industrial a la crisis de 1982. Tomo II(pp. 173-206).Monterrey: Fondo Editorial Nuevo León.

Sánchez, J. A. (2007b). Los movimientos sociales en Nuevo León. En I. Ortega (coord.)Nuevo León en el Siglo XX. La industrialización. Del segundo auge industrial a la crisis de 1982. Tomo II (pp.147173).Monterrey: Fondo Editorial Nuevo León.

Santos de la Garza, L. (2003). Los derechos humanos en materia política. Caso 10.180 México. Análisis y documentos. San Nicolás de los Garza: Facultad de Derecho y Criminología UANL.

Sartori, G. (1976). Parties and party systems: a framework for analysis.Cambridge: Cambridge UniversityPress.

Saragoza, A. (2008). La élite de Monterrey y el Estado mexicano. 1988-1940. Monterrey: Fondo Editorial Nuevo León.

Segovia, R. (1980). Las elecciones federales de 1979. Foro Internacional(3), pp. 397-410.

Smith, C., García J., y Pérez J. D. (2008). Análisis de la ideología empresarial regiomontana. Un acercamiento a partir del periódico El Norte. Confines (7),pp:11-25.

Vizcaya, I. (2006). Los orígenes de la industrialización de Monterrey: Una historia económica y social desde la caída del Segundo Imperio hasta el fin de la Revolución (1867-1920). Monterrey: Fondo Editorial Nuevo León.

Woldenberg, J.(2012).Historia mínima de la transición democrática en México. México: Colegio de México. 